\title{
Entre Freire e Castells: pensando o caso dos pré-universitários/ vestibulares populares
}

Camila Wolpato Loureiro ${ }^{1}$

\section{Resumo}

Os Pré-Universitários/Nestibulares Populares (PUP/ PVP) de matriz freireana ${ }^{2}$ estão diretamente associados a uma busca esperançosa de transformação social e democratização do acesso ao ensino superior. Em contraposição às políticas neoliberalizantes dos anos 1990, camadas populares passaram a estabelecer redes de indignação - frente a tais políticas excludentes - e de esperanças de mudança do quadro desesperador que foi colocado. De modo geral, este trabalho visa contribuir com a história da educação e do acesso a ela, estabelecendo um panorama de análise dos cursos PUP/PVP ligados às universidades federais no Estado do Rio Grande do Sul. Além disso, visa estabelecer diálogo e troca de experiências entre essas redes constituídas pelos PUP/PVP para a promoção de uma rede maior que compreenda buscas e inquietações comuns como espaços de luta e resistência das camadas populares.

\section{Palavras-chave}

Educação Popular. Pré-Universitários/Nestibulares Populares. Universidades Federais.

1. Mestranda no Programa de Pós-Graduação Interdisciplinar em Ciências Humanas da Universidade Federal da Fronteira Sul, Campus Erechim; membro do Grupo de Pesquisa Educação Popular na Universidade (GRUPEPU/ UFFS), bolsista CAPES/FAPERGS. E-mail: camilawolpato.I@gmail.com.

2. O debate sobre a obra de Paulo Freire tem suscitado dois tipos de grafias: freirianos e freireanos. A primeira está dentro da norma culta da língua portuguesa e a segunda respeita a referência a autoria intelectual de Freire. Ainda que entendamos que nenhuma está incorreta, optamos por utilizar freirianos/as, em coerência com nossa trajetória formativa e com o que aponta Ana Maria Araújo Freire. 


\title{
Between Freire and Castells: thinking the case of popular pre- universities/pre-colleges
}

Camila Wolpato Loureiro*

\begin{abstract}
The popular Pre-Universities/Pre-Colleges (PUP/ PVP) from freirean matrix are directly associated with a hopeful search of social transformation and higher education access democratization. In contrast to neoliberal policies during the 1990s, popular strata began to establish networks of indignation, against such exclusionary policies, and with hope of changing the despairing picture that has been placed. In general, this work aims to contribute with the education history and its access, establishing an analysis panorama of the PUP/PVP courses connected to federal universities, in the state of Rio Grande do Sul. Furthermore, it promotes the establishment of the dialogue and experiences exchanges between these networks of indignation and hope that the PUP/ PVP constitute, to the promotion of a larger network that understands common searches and restlessness as spaces of struggle and resistance of the popular strata.
\end{abstract}

\section{Keywords}

Popular Education. Popular Pre-Universities/PreColleges. Federal Universities.

* Master student in the Interdisciplinary Postgraduate Program in Human Sciences, Federal University of the Southern Border, Erechim Campus; member of the Popular Education Research Group at the University (GRUPEPU/UFFS), CAPES/FAPERGS fellowship.E-mail: camilawolpato.I@gmail.com. 


\section{Introdução}

Ao longo dos anos 2000 tem crescido fortemente a produção de pesquisas na área de cursos Pré-Universitários/Vestibulares Populares (PUP/PVP). Contudo, a literatura da área ainda é frágil no que tange ao trabalho colaborativo e horizontal de tentativa de implementação de práticas pedagógicas vinculadas à educação popular. A partir da análise de dados e literatura da área, propomos a construção de redes de indignações e esperanças que interligam cursos PUP/PVP associados a universidades federais no Estado do Rio Grande do Sul. Experiências essas que, mesmo respeitando as heterogeneidades de cada caso, buscam em sua base os mesmos objetivos de ampliação crítica e problematizadora do acesso ao ensino superior.

Em uma discussão teórica, na observação de grupos PUP/PVP, nos valemos de dois autores basais: Paulo Freire (1987, 1992, 2000, 2001a, 2001b), enfocando fundamentalmente os conceitos de indignação, raiva, esperança e alegria $^{3}$; e o sociólogo espanhol Manuel Castells (2013), que percebe os movimentos sociais no século XXI conectados essencialmente por redes de redes (on-line ou off-line) de atores socialmente conscientes que desenvolvem indignações e esperanças comuns ${ }^{4}$ no enfrentamento de situações consideradas por esses agentes como injustiças sociais.
Para um recorte metodológico, buscamos formas de delimitar os objetos de pesquisa, assim construímos alguns critérios, são eles: (1) estar circunscrito ao espaço geográfico do estado do Rio Grande do Sul; (2) estar necessariamente vinculado a uma universidade federal; (3) ser Pré-Universitário/Vestibular Popular.

Por fazer parte de uma pesquisa maior, o presente artigo não se propõe a investigar exaustivamente a história de cada curso pré-universitário/vestibular popular, mas fundamentalmente procura construir linhas gerais que evidenciam as redes de laços comuns compostas pelos cursos. Nesse sentido, apresentaremos quatro momentos: (1) apresentação do contexto de redução de políticas públicas de acesso ao ensino superior público no Brasil; (2) conceitos básicos para entender os cursos PUP/PVP e sua aliança com a educação popular freireana; (3) pensando Freire e Castells na análise dos cursos PUP/PVP; (4) o debate dos cursos PUP/PVP, indícios de indignações e problemas comuns.

\section{Breves considerações sobre o Neoliberalismo e educação no Brasil}

Com orientação central de abertura da educação para agentes do mercado, o

3. Ao longo do trabalho foram dirimidas as aproximações possíveis entre os conceitos freireanos de "indignação" e a "raiva" de Castells. Ambos os conceitos são elementos fundamentais para dar o estopim das lutas sociais, são esses sentimentos que mobilizam diferentes grupos para ações conjuntas e que levam ao enfrentamento de situações de opressão. Assim como a "esperança" de Freire e a "alegria" proposta por Castells, os dois sentimentos podem ser entendidos como formas de manutenção das lutas sociais. Para os autores, os/as atores que produzem as lutas sociais necessitam estar confiantes e felizes para a mobilização contínua e para que não caiam na desesperança e no cansaço. Longe de euforia per se, as lutas que buscam mudanças reais não podem conter somente tristezas e cargas pesadas, pois, se assim fossem, seriam facilmente desmanteladas. Ainda que tenhamos apontado de forma breve, é evidente a fecunda gama de possibilidades de análises de ambos os autores.

4. Conceito desenvolvido mais detalhadamente por Castells (2013) em Redes de indignação e esperança: movimentos sociais na era da internet para abordar os diferentes movimentos sociais do século XXI que, diferentemente dos séculos passados, possuem a característica central de estarem interligados por redes de indignação e esperanças comuns, no sentido de grupos que se posicionam contrários a alguma injustiça social e que influenciam outros grupos em outros lugares, desencadeando uma sucessão de acontecimentos que se propõem a mudanças sociais rápidas 
conjunto de ideias neoliberais passam a ser implementadas, no âmbito educacional, a partir da Reforma Universitária de 1968 (Lei no 5.540/68), durante a ditadura civil-militar, e acentuado, posteriormente, após a aprovação das Leis de Diretrizes e Bases (Lei no 9.394/96), durante o governo Fernando Henrique Cardoso (FHC). Evidentemente, tais medidas geraram graves consequências sobre a qualidade, o acesso e a permanência dos estudantes, alargando ainda mais a distância de trabalhadores e seus filhos de Instituições de Ensino Superior (IES).

No octênio do governo FHC, foram postas em prática uma série de reformas no Estado, tendo seus pressupostos especificados no Plano Diretor da Reforma do Aparelho do Estado (1995), no qual a privatização aparece como um dos eixos centrais. Podemos tomar como exemplo os dados coletados pelo Instituto Brasileiro de Geografia e Estatística (IBGE) nos censos de 1991 e 2000. Segundo o censo de 2000, 5,9\% (mais de um milhão) das crianças entre 10 e 14 anos, ainda eram analfabetas, destacando o fato de que as taxas elevam-se ainda mais para crianças pretas ou pardas $(9,9 \%$ e $8,5 \%)$ em relação às brancas (3,0\%). Como afirma Meneguello (1998, p. 110), "na implantação da agenda neoliberal, a reforma do Estado, foi ponto central, na qual a redução dos gastos públicos foi o mote das principais ações governamentais e se expressou na intensificação do processo de privatização e redução dos gastos sociais".

Evidentemente, tais medidas geraram graves consequências sobre a qualidade, o acesso e a permanência dos estudantes principalmente trabalhadores e seus filhos (MÉSZAROS, 2006) - no ensino superior, legitimando a qualidade da educação no viés neoliberal, no qual os filhos de trabalhadores devem ser ensinados nas artes técnicas, para sustentar o setor empresarial (FRIGOTTO, 2006). Os entraves para o acesso ao ensino básico e superior, gratuito e de qualidade, repercutiram na patente necessidade de sublevação à exclusão social. Elucidemos um pouco mais sobre o projeto neoliberal, a partir de Chaves, Lima e Medeiros (2006, p. 2):

\begin{abstract}
As reformas do Estado implementadas na América Latina nos anos 1990 tiveram como fundamento a doutrina neoliberal. De acordo com essa concepção a responsabilidade pela crise econômica dos países capitalistas é do próprio Estado que, ao longo dos anos, produziu um setor público ineficiente e marcado pelo privilégio, diferente do setor privado que desenvolve as atividades com eficiência e qualidade. Esse argumento vem sendo utilizado para justificar a necessidade de reduzir o tamanho do Estado, em especial na oferta dos serviços sociais à população. Para os defensores do neoliberalismo as conquistas sociais, como o direito à educação, à saúde, aos transportes públicos, dentre outros, devem ser regidos pelas leis do mercado, ou seja, o Estado deve liberar os serviços sociais para exploração do mercado capitalista, direcionando suas ações com vistas à reprodução do capital.
\end{abstract}

É fundamental frisarmos que a democratização do Ensino Superior não se limita à ampliação de oportunidades de acesso e criação de mais vagas, mas também que sejam proporcionados meios de permanência, isto é, meios que garantam a sobrevivência dos estudantes na vida acadêmica, tais como: auxílio moradia, alimentação, bolsas trabalho, apoio pedagógico e psicossocial etc. (CAÔN; FRIZZO, 2010).

O baixo nível de investimento em políticas públicas que promovessem transformações reais na qualidade de vida das camadas populares passou a ser pauta de diversos grupos. Intelectuais e movimentos sociais se opuseram contundentemente às políticas estatais excludentes, como é o exemplo dos PUP/PVP, a partir dos anos 1990. Nesse contexto, foram desenvolvidos grupos ligados a perspectivas emancipadoras de educação, na promoção de mecanismos que 
burlassem com a lógica desigual de acesso ao ensino superior. A sessão seguinte irá versar acerca dos grupos PUP/PVP de matriz freireana enquanto resposta para viabilizar um projeto de educação crítica, popular e latino-americana.

\section{Os cursos pré-universitários/vestibulares de matriz freireana}

Até meados dos anos 1960, a educação popular possuía uma relação de colaboração com os governos progressistas da América Latina. Nesse período, surgem o Movimento de Cultura Popular em Recife, com forte influência socialista e cristã; o Movimento de Educação de Base, criado pela Conferência Nacional de Bispos do Brasil com o apoio da presidência; o Centro Popular de Cultura, fundado pela União Nacional dos Estudantis (UNE) em 1961, utilizando a música, o teatro, e o cinema popular como espaço de formação política; além de campanhas do tipo "De pé no chão também se aprende a ler", que tiveram como objetivo a alfabetização de crianças e adultos das classes populares (MACIEL, 2011)

As experiências de educação popular passam ater maior articulação com compromissos políticos e parcerias com movimentos sociais, reafirmando que tal concepção educacional é originada de uma ampla gama de ideias e ações sociais. Brandão (2006) a entende como um fenômeno que não pode ser retirado de seu momento histórico na América Latina e, principalmente, no Brasil, onde teve o educador Paulo Freire como referência. A educação popular de matriz freiriana, entendida como a mais adequada para o tipo de análise proposta neste trabalho, também pode ser compreendida como "educação libertadora ou problematizadora", pois o autor desenvolve um paradigma educacional que valoriza e respeita os saberes e as vivências dos educandos. Durante as décadas de 1980 e 1990 a educação popular passou por um momento de reestruturação dos seus projetos e formas de lutas. Surgiram milhares de micro experiências no Brasil e na América Latina, comprometidas não apenas com as grandes lutas gerais contra as injustiças sociais, mas também com questões locais e de ordem mais direta da vida dos envolvidos.

$\mathrm{Na}$ esteira desse contexto os cursos PUP/PVP fortalecem-se enquanto espaços educacionais de defesa de um futuro esperançoso que, na análise freireana, é aquele em que é possível sonhar e agir sobre o mundo, na defesa de interesses populares. Conceitualmente, é possível compreender esses cursos como iniciativas educacionais de diversos setores da sociedade que constroem um trabalho de capacitação para o ingresso no ensino superior (ZAGO, 2008). Assim, os PUP/PVP se distanciam das concepções dos cursos pré-vestibulares comerciais que percebem a educação enquanto mercadoria. $\mathrm{Na}$ lógica mercadológica, a "educação, em todos os seus níveis, mas particularmente no superior, passa a ser entendida como uma mercadoria disponível no mercado a quem possa pagar" (PEREIRA, 2007, p. 15). Ou seja, os pré-vestibulares comerciais, sobre tal prisma, podem ser percebidos como espaços de educação potencialmente bancária, adaptada aos interesses do capital, propondo aulasshow, expositivas, dogmáticas, reducionistas que abarcam um grande número de alunos, cobrando enormes quantias de dinheiro, construindo marcas e redes de cursos nacionais, ofertando macetes e fórmulas prontas para que os alunos decorem as informações para um uso pragmático e sem relação ao mundo social.

Quantitativamente, até o ano de 2009, estimou-se que existiam cerca de 1.000 cursos PUP/PVP públicos e gratuitos ${ }^{5}$, movimentando entre 50.000 até 100.000 pessoas (PEREIRA,

5. Ainda que algumas experiências solicitem uma pequena contribuição por parte dos/as alunos/as para a manutenção física dos cursos, custeando desde aluguéis de espaços a produtos básicos de higiene e limpeza, 
2009). Foram construídos no Rio Grande do Sul, entre 1993 a 2009, 22 grupos dessa natureza (OLIVEIRA, 2009). Uma significativa parcela desses cursos está em associação direta ou indireta com universidades federais. Em sua maioria, são apresentados como projetos de extensão, para os quais as instituições dão suporte e manutenção física e humana. Talvez esse seja um dos pontos mais interessantes da reestruturação que a educação popular passou duranteosanos 1990, uma vezque suas propostas de ação partem de espaços comunitários e/ou não institucionais e encontram em Instituições de Ensino Superior (IES) públicos espaços propícios para a ampliação das suas ações. Esses passam a ser espaço de lutas conjuntas com as associações civis, por ampliação de direitos adquiridos, configurando, ao longo da história, novas frentes e possibilidades de atuação. Empiricamente, temos os exemplos das reservas de cotas (sociais e raciais), a ampliação e inscrições gratuitas nos processos seletivos, o aumento de cursos noturnos e de educação à distância (NASCIMENTO, 2003).

\section{Entre Freire e Castells: aproximações possíveis}

Percebendo os PUP/PVP de matriz freireana como espaços de formação política e de atuação dos movimentos sociais, trazemos Manuel Castells (2013), autor de Redes de indignação e esperança: movimentos sociais na era da internet. Nessa obra, o autor procura compreender as diversas etapas que compõem os movimentos reivindicatórios no século XXI. Segundo ele, para a mudança social ocorrer é necessária a ação (individual e/ou coletiva) emocionalmente engajada, que contemple sentimentos como: medo, aversão, surpresa, tristeza, alegria, raiva. Assim, a raiva seria a pólvora que faz explodir a movimentação social. Tal sentimento se dá a partir da evidência de alguma ação considerada pelo espectador como injustiça e a identificação do seu agente ocasionador. Entretanto, a mudança só acontece quando a raiva se sobrepõe ao medo - sentimento que engessa na tentativa de evitar o perigo - e quando ela é compartilhada com outras pessoas, que acabam por pensar e agir, assumindo os riscos necessários para a mudança social. Em Freire (2000), a indignação, aparece como uma das diversas lutas em busca de sonhos, ou seja, uma busca que modifica o mundo. Assim, a raiva e a indignação possuem a conotação de movimento, de atividade, de inquietação que leva à ação e acabam sendo o motor das transformações sociais.

Em Pedagogia da Esperança: um reencontro com a pedagogia do oprimido, Freire (1992) apresenta a "esperança" como o ato de esperançar, ou seja, um verbo de ação que está constantemente ligada à indignação. É, por assim dizer, uma esperança que mobiliza, que provoca a ação, e que está em consonância direta com as lutas dos movimentos sociais. A esperança de Freire (1992) necessita da prática para que vire concretude histórica, e mais, para que não caia na desesperança ou no desespero. Significa, portanto, que apesar desses fatores importantes que salientam que cada curso popular é um curso popular, que cada caso é um caso, que cada contexto é um contexto, ainda assim é possível observar que tais ações constroem espaços com indignações e esperanças comuns. Isso é o que permite a associação da obra de Castells à teoria freireana de educação quando avaliamos as "indignações" e "esperanças" dos cursos como movimentos que procuram transformações sociais importantes para as classes economicamente desfavorecidas.

Costa e Gomes (2017) propõem três características que aproximam os préuniversitários/vestibulares populares das

tais cobranças não transformam os PUP/ PVP em cursos privados, uma vez serem gritantes as diferenças de projetos político-pedagógicos e da própria compreensão de acesso à educação. 
Redes de Indignação e Esperança propostas por Castells (2013): (1) o papel das emoções nas movimentações sociais e na proposta pedagógica freireana, preocupada com uma educação política e crítica no fazer docente e discente; (2) a esperança para ambos os autores não é a imobilista, mas sim ativa e fundamental na constante reorganização das lutas; (3) a autorreflexão, apontando tanto as manifestações analisadas por Castells, quanto os PUP/ PVP se preocupam em se repensar constantemente, abordando temas sociais e problematizadores. Seguindo e indo além, apontamos aqui, outros três pontos que julgamos relevantes para analisar a aproximação desses cursos das ideias de Castells, são eles: (1) o aspecto de horizontalidade dos movimentos sociais; (2) a abertura e maleabilidade das redes; (3) efetivação constante da mudança em prol das (auto) avaliações.

O suporte teórico do sociólogo espanhol serve para a interpretação dos cursos populares, mas não foi pensado para esses grupos. Visualizando de forma crítica, Costa e Gomes (2017) não apontam em quais momentos a obra de Castells se distancia das realidades apresentadas pelos cursos PUP/PVP. Dessa maneira, esboçamos dois aspectos em que podem ser observadas distinções entre o caso dos cursos populares e as perspectivas de Castells: (1) os movimentos que o autor analisa possuem a características de rapidez: em poucos dias ou meses os grupos se organizam e constroem as bases das mudanças sociais. Diferentemente, a construção dos PUP/ PVP são processos demorados que podem chegar a décadas até suas consolidações e evidências de transformações sociais. A morosidade dos processos se dá por seu caráter políticopedagógico que entende que as mudanças só podem ser concretas quando seus agentes se perceberem conscientes historicamente de si no mundo; (2) a compreensão do autor de que os movimentos analisados, em uma tentativa de manutenção de suas autonomias, são totalmente contrários às instituições atuais, propondo alternativas para novas formas de pensar o mundo. Contudo, os grupos analisados aqui vão de encontro a esse entendimento, uma vez que estão ligados de forma institucional às universidades federais, ao passo que mantém o caráter autogestionado dos movimentos. Então, pensamos que a institucionalização não prevê a perda total de autonomia, mas sim a possibilidade de novas formas e frentes de transformações sociais; os PUP/PVP institucionais permeiam e se utilizam dos meios que a própria instituição fornece para aparelhagem de suas pautas e chegar ao seu fim maior de democratização de acesso ao ensino superior.

Entendemos ser fundamental pensarmos no estabelecimento de redes (internas e externas) nos PUP/PVP enquanto espaços de ações coletivizadas e colaborativas, em que as trocas de experiências sejam pontos-chave para o andamento das atividades. Para além de evidenciar tais necessidades, propomos formas diretas de construção de linhas de diálogo, que viabilizem o aprimorando da comunicação no (e com) o presente e sobre (e com) o passado. Como: (1) conservação e disponibilização online de telefones para contato, endereços de e-mail e outros canais digitais de comunicação; (2) produção e um adequado armazenamento de materiais de registro, como atas, documentos de fundação, bibliografias e trabalhos acadêmicos produzidos nos grupos; (3) organização e disponibilização de arquivos internos de forma online, aberta e gratuita; (4) promoção da construção de arquivos e documentos relevantes em coautoria, coprodução e colaboração on-line; (5) fomento a mais ações de diálogo direto, seja em congressos ou rodas de conversa, trabalhos de investigação histórica interna e externamente aos grupos; (6) projetos, parcerias e ampliações de ações de forma interinstitucional; (7) pesquisas colaborativas entre PUP/PVP, que possam, inclusive, mas não 
somente, evidenciar as Redes de Indignação e Esperança; (8) documentos e posicionamentos elaborados conjuntamente e de forma horizontal entre PUP/PVP; (9) construção de um repositório coletivo, on-line e de amplo acesso de materiais didáticos e atividades interdisciplinares.

\section{Os cursos pré-universitários/vestibulares populares no Rio Grande do Sul}

Como já foi apontado anteriormente, a fim de delimitar os cursos investigados, fizemos alguns percursos metodológicos, tais como: (1) busca em redes sociais, blogs e sítios oficiais de universidades; (2) análise da bibliografia da área, observando textos que mencionavam ou listavam os cursos PUP/PVP no Rio Grande do Sul; (3) observação acerca de quais cursos participaram doIVEncontro dePré-Universitários Populares, ocorrido em setembro de 2016, na cidade de Santa Maria-RS; (4) entrevistas com membros de cursos, que citavam ou possuíam conhecimento de outros grupos semelhantes.

Foram coletadas documentações, entre elas: escritos oficiais, fontes de jornais on-line e impressos, vídeos de divulgação e fotografias do cotidiano e de momentos importantes dos grupos explorados, além de um questionário final, inquerindo acerca das dificuldades e problemas enfrentados nos cursos. As fontes foram recolhidas de diferentes locais: (a) sítios e páginas oficiais dos cursos e Universidades; (b) arquivos físicos dos cursos; (c) arquivos pessoais, espontaneamente disponibilizadas por coordenadores/as e/ou professores/as. Em um segundo momento, foram coletadas 22 entrevistas semiestruturadas ${ }^{6}$, de (ex) alunos/ as, (ex)professores/as e coordenadores/as dos cursos observados.

Chegamos, assim, a seis cursos PUP/PVP ligados às universidades federais e que possuem um viés freireano de educação, são eles: (1) Curso Pré-Vestibular Popular Desafio (PVPDesafio), UFPel; (2) Curso Práxis - Coletivo de Educação Popular, UFSM; (3) Curso PréUniversitário Popular Alternativa (PUPA), UFSM; (4) Cursinho Pré-Vestibular Popular Esperança Restinga, UFRGS; (5) Programa de Auxílio ao Ingresso ao Ensino Técnico e Superior (PAIETS), FURG; (6) Curso LEME: oficinas preparatórias para o ENEM, UNIPAMPA.

Em função de uma delimitação de páginas, o presente artigo não irá abordar de forma detalhada cada um dos cursos analisados. Para compreender as questões gerais apontadas no trabalho, observaremos os grupos em blocos, por meio de questionamentos norteadores. A primeira pergunta "Onde e quando surgiu o PUP/PVP?" busca apontar os diferentes contextos de fundação dos cursos. Foi possível observar que os grupos desenvolveramse em dois momentos principais: em um primeiro, durante as emergências dos anos 1990 e ano 2000 e, em um segundo momento, durante os anos 2006 e 2015. $\mathrm{O}$ primeiro elemento diz respeito à escassa ou inconstante afinidade do corpo docente para com as práticas de educação libertadora. Os motivos para esse fenômeno são voláteis e dependentes de cada experiência com seu devido contexto espacial e histórico e pode ser compreendido com o estabelecimento de linhas gerais de análise, tais como: (1) falta de harmonia interna entre o grupo em definir

6. Todas as entrevistas foram concedidas livremente com a assinatura de termo livre e esclarecido concedendo o direito de uso do som da voz, da imagem, nome e dados biográficos dos (as) educadores (as). Deste montante de entrevistas, pelo menos 13 foram obtidas durante o desenvolvimento do projeto "Pesquisa Histórica", construído por um grupo de educadores (as) que majoritariamente cursavam o curso de História da UFSM. Como ação comemorativa aos 15 anos de existência do curso, tinha por objetivo fazer um resgate da história do PréUniversitário Popular Alternativa. As outras 8 entrevistas foram captadas pela pesquisadora em dois momentos: (a) durante o IV Encontro de Pré-Universitários Populares, ocorrido em Santa Maria em setembro de 2016; (b) em visitas in loco aos cursos PUP's/PVP's. 
demandas coerentes para com a perspectiva da educação popular; (2) falta de conhecimento acerca das formas de abordagem propostas nas obras freireanas; (3) falta de formações continuadas entre o corpo docente; (4) falta de diálogo interno e entre cursos PUP/PVP que possibilitem a aproximação empírica das discussões de Freire com a realidade de cada curso; (5) formação acadêmica com lacunas. Esta última é apontada como uma das maiores dificuldades para os docentes iniciantes, que atuam em cursos PUP/PVP. Tal formação aliada às expectativas pessoais e dos/as educandos/as, pressionam e contribuem para um fazer docente precário e distante das perspectivas pedagógicas da educação popular. Uma educadora do curso Maxximus - PAIETS apontou que a coesão entre discurso e prática, além de um comprometimento responsável e amoroso, faz parte da perspectiva contra-hegemônica freireana. Ela pontua, ainda, que é fundamental o respeito e o cuidado dos/as educadores/as para com os sonhos dos/das educandos/as de ingresso no ensino superior, não deixando sobrepor sua proposta pedagógica de transformação social aos objetivos fins dos/das alunos/as.

A precária infraestrutura básica indicou, ao longo da pesquisa, a necessidade de constante reafirmação da relevância dos cursos para a comunidade assistida, para a formação dos acadêmicos e também para a própria universidade. As entrevistas e falas extraoficiais de membros de diferentes cursos PUP/PVP demonstram a enorme preocupação quanto à falta de repasses de verbas, seja para o auxílio de manutenção dos/as educadores/ as, como bolsas e verbas para transportes, seja para compra de materiais de higiene básica ou pagamento das contas para a manutenção do espaço ocupado. O pouco ou nenhum auxílio das instituições às quais os PUP/PVP estão vinculados dificulta ainda mais a construção e uma educação pautada na dialogicidade e na quebra das estruturas formais. Um educador do curso PVP-Desafio, aponta que, mesmo na experiência mais antiga no Rio Grande do Sul, ainda existem dificuldades e necessidade de reafirmação constante da importância do curso. Uma dessas dificuldades apontadas é a obtenção de materiais de higiene básicos, bem como de manutenção do prédio alugado pela UFPel para o funcionamento do curso. Já um educador do Coletivo Práxis também coloca como dificuldade cotidiana enfrentada pelo projeto o apoio da Universidade Federal de Santa Maria (UFSM) com materiais didáticos e de escritório.

O corpo docente itinerante e falta de professorestambémfoicolocadocomoumgrande desafio dos cursos e demonstra a inconsistência do quadro docente, em função do elevado número de professores sazonais ou passageiros. A falta de educadores/as para as áreas temáticas exigidas nos processos seletivos evidencia uma fragilidade na agregação e manutenção de educadores/as nos cursos, gerando outros tantos problemas, como: a falta de pessoas para efetivar a autogestão dos cursos; baixa capacitação dos/as educandos/as para as provas seletivas; pouca oxigenação do quadro docente.

O quarto e último ponto, a evasão discente, dialoga acerca das contradições entre o discurso afinado com as perspectivas freireanas e da educação popular, com as práticas cotidianas que distanciam os/as educandos/as dos cursos. Motivados por diferentes fatores, a desistência deles/delas podem decorrer de: (1) motivos internos como falta de infraestrutura mínima; de materiais didáticos; tensão em relação às perspectivas freireanas de educação; (2) motivos externos como problemas familiares, perda de emprego, gravidez, falta de apoio familiar, descrença em suas capacidades de alcançar as notas necessárias para a seleção nos processos seletivos, falta de dinheiro para pagar as passagens de ônibus até o curso etc.

A partir desses questionamentos norteadores, podemos pensar os cursos conectados em "Redes de Indignação e 
Esperança" dentro de redes maiores que interligam os grupos. Entendemos a importância do diálogo das redes com o presente e o passado, tanto internamente em cada rede, quanto externamente, em diálogo com outros grupos. O desenvolvimento de encontros internamente e entre os cursos, para trocas de experiências e aprendizados; a formação em educação popular dentro dos grupos, com discussões de textos clássicos e atuais; o diálogo com a história de luta interna do curso e também, de outros grupos, são algumas estratégias possíveis de estreitamento dessas linhas de diálogos.

\section{Considerações finais}

Os PUP/PVP institucionais do Rio Grande do Sul podem ser entendidos como espaços de lutas pela democratização e pelo acesso ao ensino superior, que abarcam problemas, angústias, alegrias e felicidades parecidas entre si.

O presente artigo se propôs a verificar as linhas que ligam e interligam as redes desses grupos, observando as indignações e as esperanças comuns produzidas por cada experiência. Assim, em consonância com as ideias propostas por Castells (2013), os grupos possuem indignações e esperanças que os conectam, de forma on-line e off-line, na busca por transformações sociais.

Evidencia-se, a partir do estudo, que as lutas travadas pelas redes dos PUP/PVP estão sob permanentes riscos e ameaças de elites hegemônicas. Faz-se necessário, portanto, entendermos que esses cursos, em toda a sua complexidade, enfrentam problemas e dificuldades que perpassam questões de estrutura física, afinamento com as perspectivas teórico-metodológicas da educação popular, desconhecimento do passado do grupo, entre outros.

Pensamos que o colocado aqui possui o caráter de convite à discussão, sobretudo para entendermos que cada experiência compõe uma série de microrredes internas, de relações que são estabelecidas em diferentes níveis dentro do mesmo espaço por motivações diversas, como, entre os membros de cada disciplina, entre os/as educadores/as que ministram aula em um mesmo dia, entre educadores/as e uma turma específica. Além de observar as histórias de lutas e ações de resistência e as experiências e construções formativas desses educadores/as, é fundamental que outras produções sejam feitas, tanto para servir de novos canais para estreitar as conexões internas e externas das redes de PUP/PVP, quanto perspectivas inovadoras de análises dos grupos.

\section{Referências}

BRANDÃO, C. R. O que é educação popular? São Paulo: Brasiliense, 2006. 95 p. (Coleção Primeiros Passos).

CASTELLS, M. A sociedade em rede. 10. ed. São Paulo: Paz e Terra, 2007. 698 p.

Redes de indignação e esperança: movimentos sociais na era da internet. Rio de Janeiro: Zahar, 2013. 271 p.

COSTA, A. R.; GOMES, T. F. Contribuições da obra de Paulo Freire nos encontros de cursos préuniversitários populares: redes de indignação e esperança. Revista de Educação Popular, Uberlândia, v. 16, n. 2, p. 137-151, maio-ago. 2017. Doi: http://dx.doi.org/10.14393/REP_v16n22017_rel01. 
CAÔN, G. F.; FRIZZO, H. C. F. Acesso, equidade e permanência no ensino superior: desafios para o processo de democratização da educação no Brasil. Revista Vertentes, São João del Rei, v. 19, n. 2, 2010.

FREIRE, P. À sombra da mangueira. São Paulo: Olho D'água, 2001. 224 p

. Pedagogia da esperança: um reencontro com a pedagogia do oprimido. Rio de Janeiro: Paz e Terra, 1992. 245 p.

. Pedagogia da indignação: cartas pedagógicas e outros escritos. São Paulo: Editora da UNESP, 2000. 134 p.

. Pedagogia do oprimido. 17. ed. Rio de Janeiro: Paz e Terra, 1987. 184 p.

. Política e educação. 5. ed. São Paulo: Cortez, 2001. 144 p.

LOUREIRO, C. W. Redes de indignação e esperança: o caso dos pré-universitários/ vestibulares populares no Rio Grande do Sul nas décadas de 1990 e 2000. 1997. Trabalho de Conclusão de Curso (Graduação em História) - Universidade Federal de Santa Maria, Santa Maria, 2017.

MACIEL, K. O pensamento de Paulo Freire na trajetória da educação popular. Educação em Perspectiva, Viçosa, v. 2, n. 2. p. 326-344, jul.-dez. 2011.

MENEGUELLO, R. Partidos e governos no Brasil contemporâneo (1985-1997). São Paulo: Paz e Terra, 1998. 205 p.

MÉSZAROS, I A educação para além do capital. São Paulo: Boi Tempo Editorial, 2006. 77 p.

NASCIMENTO, A. No entrechoque da educação básica com a educação superior: cursinhos militantes. UNICiência, Cuiabá, v. 7, n. 1, p. 27-50, 2003.

OLIVEIRA, C. Os pré-universitários populares como espaço de educação política: o caso do Práxis. 2009. 142f. Dissertação (Mestrado em Educação) - Universidade Federal de Santa Maria, Santa Maria, 2009.

PEREIRA, T. Pré-vestibulares em Porto Alegre na fronteira entre o público e o privado. 2007. 164f. Dissertação (Mestrado em Educação) - Universidade Federal do Rio Grande do Sul, Porto Alegre, 2007.

PEREIRA, I. C. A relação entre formação inicial do professor de geografia da UFSM e os prévestibulares Alternativa e Práxis: a perspectiva do pronunciamento da palavra. 2009. 75f. Trabalho de Conclusão de Curso (Especialização em Gestão Educacional) - Universidade Federal de Santa Maria, 2009.

ZAGO, N. Cursos pré-vestibulares populares: limites e perspectivas. Perspectiva, Florianópolis, v. 26, n. 1, p. 149-174, jan.-jun. 2008.

Submetido em 2 de junho de 2018.

Aprovado em 21 de agosto de 2018. 